\title{
Theoretical Investigation of Excited-State Single and Double Proton Transfer Mechanisms for 2,5-bis(benzoxazol-2-yl)thiophene-3,4-diol
}

\author{
Jin-Dou Huang ${ }^{1}$, Kun $\mathrm{Yu}^{2}$, Huipeng $\mathrm{Ma}^{*^{2}}$, Shuo $\mathrm{Chai}^{3}$, and Bin Dong $*^{1}$ \\ ${ }^{1}$ School of Physics and Materials Engineering, Dalian Nationalities University, Dalian 116600, \\ China \\ 2 College of Medical Laboratory Science, Dalian Medical University, Dalian 116044, China \\ ${ }^{3}$ School of Physics and Optoelectronic Technology, Dalian University of Technology, Dalian \\ 116024, China
}

* Corresponding author. E-mail address: hpma@dlmedu.edu.cn (Huipeng Ma), and dong@dlnu.edu.cn (Bin Dong).

\begin{abstract}
In this work, excited-state intramolecular single and double proton transfer mechanisms for 2,5-bis(benzoxazol-2-yl)thiophene-3,4-diol were investigated using time-dependent density functional theory (TDDFT) method for the first time. Our calculations showed that the intramolecular hydrogen bond $\mathrm{N}^{\cdots} \mathrm{H}-\mathrm{O}$ is strengthened in the excited state, which provides a driving force to effectively facilitate the proton transfer process. The constructed potential energy surfaces of the ground state and excited state demonstrated that the double proton transfer reaction occurs more readily in both dynamics and thermodynamics aspects, and it is implemented by simultaneous double proton transfer, or successive single transfers. Furthermore, the assignments of multiple fluorescence bands in experiment were confirmed by fluorescence spectral simulation. The calculated emission spectra indicated that the experimental fluorescence maxima at $475 \mathrm{~nm}$ should be attributed to normal Stokes shifted emission; the large Stokes shifted fluorescence with peaks at $550 \mathrm{~nm}$ originates from the double proton transfer phototautomer emission, and the experimentally observed shoulder peak at $\sim 493 \mathrm{~nm}$ results from the excited state single proton transfer tautomer.
\end{abstract}

Keywords: Excited-state double proton transfer mechanisms; Hydrogen bond strengthening; Potential energy surfaces; Electronic spectra simulation; intramolecular charge transfer 


\section{Introduction}

As one of the most important elementary reaction in materials and biological systems, excited-state intramolecular/intermolecular proton transfer (ESIPT) reaction has attracted wide attention since it was observed by Weller et al., ${ }^{1}$ and was revitalized recently due to its importance in a variety of photochemical and biological processes. ESIPT represents a complicated phototautomerization process and usually involves the transfer of a hydroxyl/imino proton from a preexisting hydrogen bond to an oxygen or nitrogen acceptor atom in the excited state, resulting in a new isomer dubbed as a proton-transfer tautomer or phototautomer. Owing to the drastic structural alternation, the phototautomer possesses different photophysical properties from that of the original (normal) species, offering great versatility in a variety of applications, such as fluorescent chemosensors, ${ }^{2-4}$ lasing materials, ${ }^{5}$ photostabilizers, ${ }^{6-7}$ molecular recognition, ${ }^{8-10}$ solid state emitters, ${ }^{11-15}$ and so forth

Among different ESIPT reactions, excited state double or multiple proton transfer reactions have been investigated by many researchers in the last few years because of its intrinsic property in mimicking proton relay in vital bio-systems. In 2015, Zhao et al. investigated photophysical properties of 3-hydroxyisoquinoline and bis-2,5-(2-benzoxazolyl)-hydroquinone in detail, and reconfirmed the excited-state single and double proton transfer mechanisms of these compounds using time-dependent density functional theory (TDDFT) method and provided a reasonable explanation for the fluorescence quenching phenomenon observed experimentally. ${ }^{16-17}$ Very recently, Chen et al. strategically designed and synthesized a new compound of 2,5-bis(benzoxazol-2-yl) thiophene-3,4-diol to explore single proton transfer and double proton transfer in the excited state. ${ }^{18}$ Fluorescence emission and decay spectra showed that single and double proton transfer may proceed via synchronous or asynchronous types of double proton-transfer or even more complicated multiple pathways. However, the mechanism of double proton transfer which undergoes one-step or stepwise process is still unclear due to the lack of ultrafast time-resolved spectrometer and systematically theoretical investigations. In order to clearly elucidate the proton transfer mechanisms, we are motivated to theoretically study the ground state and excited states of 2,5-bis(benzoxazol-2-yl) thiophene-3,4-diol relevant to the hydrogen transfer mechanism using density functional theory (DFT) and time-dependent density 
functional theory (TD-DFT) method, respectively. Firstly, the geometric optimizations of the molecule in different conformations have been performed, and the influence of optical excitation and solvent effect on the properties of intramolecular hydrogen bonds were discussed in detail. Furthermore, the direct and definite informations about the excited-state proton transfer mechanism were proposed by investigating the homologous ground-state $\left(\mathrm{S}_{0}\right)$ and the first excited state $\left(\mathrm{S}_{1}\right)$ potential energy surfaces/curves of 2,5-bis(benzoxazol-2-yl) thiophene-3,4-diol. Based on the stable conformations on the PESs or PECs, the electronic spectra and frontier molecular orbitals were calculated and analyzed theoretically. The remainder of this article is organized such as that the following section describes the computational methods. Section 3 describes and discusses the results of the DFT calculations, which is organized by subsection that geometry structure, potential energy surfaces/curves and proton transfer process, and then electronic spectra simulation and frontier molecular orbitals analysis. A final section summarizes and gives the conclusions of this study.

\section{Computational Methods}

In the present work, all electronic structure calculations were carried out with the Gaussian 09 program suite. ${ }^{19}$ Geometry optimizations of 2,5-bis(benzoxazol-2-yl)thiophene-3,4-diol molecule at $\mathrm{S}_{0}$ state and the $\mathrm{S}_{1}$ state were implemented using DFT method and TD-DFT method, respectively. Previous studies have proven that the TD-DFT method is a useful tool to describe hydrogen bonding in the excited states of possibly hydrogen bond systems $;{ }^{20-21}$ and the Becke's three-parameter hybrid exchange functional with Lee-Yang-Parr gradient-corrected correlation $\left(\mathrm{B}_{3} \mathrm{LYP} \text { functional }\right)^{22}$ and triple-zeta valence quality with one set of polarization functions $(\mathrm{TZVP})^{23}$ is the appropriate functional and basis set for most organic compounds. ${ }^{16-17,24-25}$ In our previous study, the test with a series of functionals and basis sets, such as $B_{3} L Y P / T Z V P$, $\mathrm{B}_{3} \mathrm{LYP} \mathrm{D}_{3} / \mathrm{TZVP}$ and CAM-B ${ }_{3} \mathrm{LYP} / \mathrm{def}_{2}$-qzvpd, was performed for 3-hydroxy-2-(thiophen-2-yl) chromen-4-one, which showed that the geometry structures optimized using $\mathrm{B}_{3} \mathrm{LYP} / \mathrm{TZVP}$ is very similar to the ones optimized by the $\mathrm{B}_{3} \mathrm{LYP}-\mathrm{D}_{3} / \mathrm{TZVP}$ for the ground state, and the UV-Vis spectra based on these structures are nearly the same; and comparison of the performances of $\mathrm{B}_{3} \mathrm{LYP} / \mathrm{TZVP}$ and CAM- $\mathrm{B}_{3} \mathrm{LYP} / \mathrm{def}_{2}$-qzvpd methods suggested the $\mathrm{B}_{3} \mathrm{LYP} / \mathrm{TZVP}$ results are in better agreement with the experimental fluorescence spectra. ${ }^{26}$ Therefore, we selected 
$\mathrm{B}_{3} \mathrm{LYP} / \mathrm{TZVP}$ in our DFT and TD-DFT calculations. The self-consistent field (SCF) convergence thresholds of the energy for both the $S_{0}$ state and $S_{1}$ state optimization were used the default setting $\left(10^{-6}\right)$. The geometry optimizations were performed without constraints on bond lengths, angles, or dihedral angles except constructing potential energy surfaces (PESs) and potential energy curves (PECs). The $\mathrm{S}_{0}$ and $\mathrm{S}_{1}$ PESs/PECs have been scanned by constrained optimizations to obtain the thermodynamic corrections in corresponding electronic state and keeping the $\mathrm{O}-\mathrm{H}$ distance fixed at a series of values. All the local minima were confirmed by the absence of an imaginary mode in vibrational analysis calculations. To evaluate the solvent effect, $\mathrm{CHCl}_{3}$ was selected as the solvent in the calculations using the conductor-like screening model (COSMO) method. ${ }^{27}$

\section{Results and Discussions}

\subsection{Geometry Structures}

For 2,5-bis(benzoxazol-2-yl)thiophene-3,4-diol molecule, the possible stable conformations in $\mathrm{S}_{0}$ state and $\mathrm{S}_{1}$ state are shown in Scheme 1. Without considering intramolecular proton transfer reaction, the conformations at $S_{0}$ state are donated by $\mathbf{a}, \mathbf{b}$, and $\mathbf{c}$, and the corresponding conformations at the $S_{1}$ state are marked with asterisk, $\mathbf{a}^{*}, \mathbf{b}^{*}$, and $\mathbf{c}^{*}$. The calculated potential energies of these structures in ground state and excited state are collected in Table S1. For $\mathrm{S}_{0}$ state, a showed the lowest energy, which is about $4.55 \mathrm{kcal} / \mathrm{mol}$ and $9.25 \mathrm{kcal} / \mathrm{mol}$ lower than $\mathbf{b}$ and $\mathbf{c}$, respectively; and for the $S_{1}$ state, the energies of $a^{*}$ is about $4.69 \mathrm{kcal} / \mathrm{mol}$ and $9.61 \mathrm{kcal} / \mathrm{mol}$ lower than those of $\mathbf{b}^{*}$ and $\mathbf{c}^{*}$, respectively. It indicates that the $\mathbf{a}$ and $\mathbf{a}^{*}$ structures are most stable conformations of 2,5-bis(benzoxazol-2-yl)thiophene-3,4-diol molecule in $\mathrm{S}_{0}$ state and $\mathrm{S}_{1}$ state, respectively, and they should contribute most to the experimental absorption spectra and fluorescence spectra, respectively. Moreover, it should be noted that the relatively small energy difference between $\mathbf{a}\left(\mathbf{a}^{*}\right)$ and $\mathbf{b}\left(\mathbf{b}^{*}\right)$ suggests that $\mathbf{b}\left(\mathbf{b}^{*}\right)$ also makes some contribution to experimental spectra, in comparison, $\mathbf{c}\left(\mathbf{c}^{*}\right)$ contributes little to experimental spectra due to its relatively high energy and low stability.

Structurally, a and c separately includes $\mathrm{N}^{\cdots} \mathrm{H}-\mathrm{O}$ intramolecular hydrogen bonds and $\mathrm{O} \cdots \mathrm{H}-\mathrm{O}$ intramolecular hydrogen bonds; and both $\mathrm{N}^{\cdots} \mathrm{H}-\mathrm{O}$ and $\mathrm{O} \cdots \mathrm{H}-\mathrm{O}$ intramolecular hydrogen bonds 
were simultaneously formed in $\mathbf{b}$. We numerically labeled atoms connected to the hydrogen bonds to describe them more clearly (see Scheme 1). For the ground state $\mathrm{S}_{0}$, the calculated bond lengths, bond angles and dihedral angles of various hydrogen bonds are listed in Table 1. The optimized results of $\mathrm{N} \cdots \mathrm{H}-\mathrm{O}$ hydrogen bonds in a shows that $\mathrm{O}_{1}-\mathrm{H}_{1}$ bond length is $0.985 \AA \mathrm{N}_{1} \cdots \mathrm{H}_{1}$ distance is $1.902 \AA$, and the bond angle $\angle \mathrm{N}_{1} \cdots \mathrm{H}_{1}-\mathrm{O}_{1}$ is about $142.5^{\circ}$. These structure characters indicate the formation of a strong intramolecular hydrogen bond $\left(\mathrm{N}_{1} \cdots \mathrm{H}_{1}-\mathrm{O}_{1}\right)$. In comparison, the $\mathrm{O}_{1}-\mathrm{H}_{1}$ bond length and $\mathrm{O}_{2} \cdots \mathrm{H}_{1}$ distance in the $\mathrm{O}_{2} \cdots \mathrm{H}_{1}-\mathrm{O}_{1}$ hydrogen bonds of $\mathbf{c}$ is $0.969 \AA$ and $1.987 \AA$, respectively, and the bond angle $\angle \mathrm{O}_{2} \cdots \mathrm{H}_{1}-\mathrm{O}_{1}$ is about $137.6^{\circ}$, indicating $\mathrm{O}_{2} \cdots \mathrm{H}_{1}-\mathrm{O}_{1}$ hydrogen bond is relatively weaker than $\mathrm{N}_{1} \cdots \mathrm{H}_{1}-\mathrm{O}_{1}$. It is consistent with the former energy analysis results that the $\mathrm{N}^{\cdots} \mathrm{H}-\mathrm{O}$ hydrogen bonds decrease the molecular energy more effectively compared to $\mathrm{O} \cdots \mathrm{H}-\mathrm{O}$ hydrogen bonds.

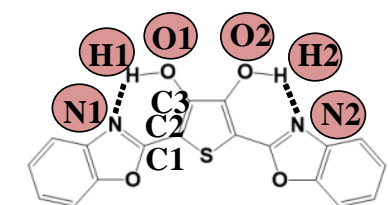

$\mathbf{a}$

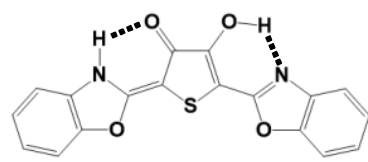

a-1

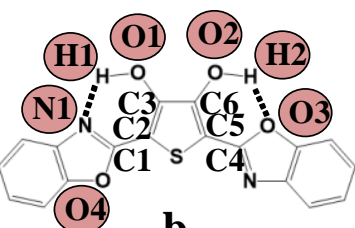

b

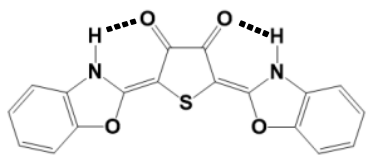

a-2

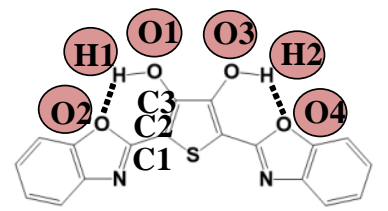

c

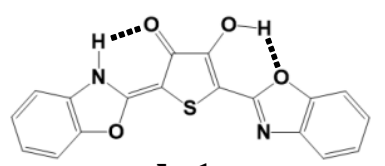

b-1

Scheme 1. Molecular structures of 2,5-bis(benzoxazol-2-yl)thiophene-3,4-diol in different conformations.

The structure parameters of intramolecular hydrogen bonds in $\mathbf{a}^{*}, \mathbf{b}^{*}$ and $\mathbf{c}^{*}$ are also collected in Table 1. Compared with the hydrogen bonds of a and $\mathbf{c}$ at $\mathrm{S}_{0}$ state, the $\mathrm{O}_{1}-\mathrm{H}_{1}$ bond length has little varations, however, the $\mathrm{N}_{1} \cdots \mathrm{H}_{1}$ distance and $\mathrm{O}_{2} \cdots \mathrm{H}_{1}$ distance become shorter; the bond angles $\angle \mathrm{N}_{1} \cdots \mathrm{H}^{-} \mathrm{O}_{1}$ in a changes from $142.5^{\circ}$ to $143.8^{\circ}$, and $\angle \mathrm{O}_{2} \cdots \mathrm{H}-\mathrm{O}_{1}$ in $\mathbf{c}$ changes from $137.7^{\circ}$ to $139.3^{\circ}$. These structural variations suggest that the intramolecular hydrogen bonds $\mathrm{N}_{1} \cdots \mathrm{H}_{1}-\mathrm{O}_{1}$ and $\mathrm{O}_{2} \cdots \mathrm{H}_{1}-\mathrm{O}_{1}$ in the $\mathrm{S}_{1}$ state were more stable than those in the $\mathrm{S}_{0}$ state. Interestingly, the two types of hydrogen bonds in $\mathbf{b}$ exhibit opposite trend in the photoexcitation process. For the $\mathrm{N}_{1} \cdots \mathrm{H}_{1}-\mathrm{O}_{1}$ hydrogen bond of $\mathbf{b}^{*}$, the $\mathrm{O}_{1}-\mathrm{H}_{1}$ bond length becomes slightly longer and the $\mathrm{N}_{1} \cdots \mathrm{H}_{1}$ distance become shorter than the ones at $\mathrm{S}_{0}$ state, suggesting the $\mathrm{N}_{1} \cdots \mathrm{H}_{1}-\mathrm{O}_{1}$ hydrogen bond 
strengthening; in contrast, for $\mathrm{O}_{3} \cdots \mathrm{H}_{2}-\mathrm{O}_{2}$ hydrogen bond in $\mathbf{b}^{*}$, the $\mathrm{O}_{2}-\mathrm{H}_{2}$ bond length becomes slightly shorter and the $\mathrm{O}_{3} \cdots \mathrm{H}_{2}$ distance become longer than the ones at $\mathrm{S}_{0}$ state, which demonstrates the $\mathrm{O}_{3} \cdots \mathrm{H}_{2}-\mathrm{O}_{2}$ hydrogen bond is weakened. Thus, the $\mathrm{N}_{1} \cdots \mathrm{H}_{1}-\mathrm{O}_{1}$ hydrogen bond in $\mathbf{b}^{*}$ is more stable than the ones in $\mathbf{a}^{*}$, and $\mathrm{O}_{3} \cdots \mathrm{H}_{2}-\mathrm{O}_{2}$ hydrogen bond is less stable than the ones in $\mathbf{c}^{*}$. It can be concluded that $\mathrm{N}_{1} \cdots \mathrm{H}_{1}-\mathrm{O}_{1}$ hydrogen bond strenghthening in $\mathbf{b}^{*}$ could decrease the molecular energies more effectively, and the most stable $\mathbf{b}^{*}$ structure is consequence of competition between the two different hydrogen bond structures. Also, the inter-ring torsion angles (dihedral angle $\mathrm{O}_{4}-\mathrm{C}_{1}-\mathrm{C}_{2}-\mathrm{C}_{3}$ ) of $\mathbf{b}^{*}$ are more closed to the one in $\mathbf{a}^{*}$, which also suggests that $\mathbf{b}^{*}$ prefers to form the more stable $\mathrm{N}_{1}{ }^{\cdots} \mathrm{H}_{1}-\mathrm{O}_{1}$ hydrogen bond rather than the $\mathrm{O}_{3} \cdots \mathrm{H}_{2}-\mathrm{O}_{2}$ hydrogen bond.

In order to investigate the solvent effect on the intramolecular hydrogen bond and conveniently compare with available experimental results, trichloromethane $\left(\mathrm{CHCl}_{3}\right)$ were used in the conductor-like screening model of solvation. The related structure parameters of the stable structures are also collected in Table 1. For the $\mathrm{S}_{0}$ state, we can see that the $\mathrm{O}_{1}-\mathrm{H}_{1}$ bond length in $\mathrm{CHCl}_{3}$ increases by $0.001-0.002 \AA, \mathrm{N}_{1} \cdots \mathrm{H}_{1}$ distance in $\mathrm{N}_{1} \cdots \mathrm{H}_{1}-\mathrm{O}_{1}$ hydrogen bond decreases by $0.006-0.007 \AA$, and $\mathrm{O}_{2} \cdots \mathrm{H}_{1}$ distance in $\mathrm{O}_{2} \cdots \mathrm{H}_{1}-\mathrm{O}_{1}$ hydrogen bond increase by $0.010-0.012 \AA$ compared with the case in gas phase, which suggests that the solvent effect of $\mathrm{CHCl}_{3}$ enhances the $\mathrm{N}_{1} \cdots \mathrm{H}_{1}-\mathrm{O}_{1}$ hydrogen bond and weakens the $\mathrm{O}_{2} \cdots \mathrm{H}_{1}-\mathrm{O}_{1}$ hydrogen bond in the molecule. Furthermore, the energies of $\mathbf{a}, \mathbf{b}$, and $\mathbf{c}$ in $\mathrm{CHCl}_{3}$ were calculated, as shown in Table S1. It is found that the energies of $\mathbf{a}, \mathbf{b}$, and $\mathbf{c}$ decrease $4.13 \mathrm{kcal} / \mathrm{mol}, 4.95 \mathrm{kcal} / \mathrm{mol}$ and $5.83 \mathrm{kcal} / \mathrm{mol}$, respectively, compared with the case in gas phase. The solvent effect apparently lowered the molecular energies, especially for the $\mathbf{b}$ and $\mathbf{c}$. Therefore, we believe that $\mathbf{b}$ should contribute more to absorption spectra in the $\mathrm{CHCl}_{3}$ due to the solvent effect. The structure parameters of $\mathbf{a}^{*}, \mathbf{b}^{*}$ and $\mathbf{c} *$ in $\mathrm{CHCl}_{3}$ are also shown in Table 1 . Comparison of geometry structures in $\mathrm{S}_{1}$ state and in $\mathrm{S}_{0}$ state shows that the geometries of the $\mathbf{a}, \mathbf{b}$ and $\mathbf{c}$ retain their planar structures or quasi-planar structures in the transition from $S_{0}$ to $S_{1}$, and the bond angles of hydrogen bond in the $S_{1}$ state are more close to $180^{\circ}$ than the ones in the $\mathrm{S}_{0}$ state. More importantly, the $\mathrm{N}_{1} \cdots \mathrm{H}_{1}$ distance in $\mathbf{a}^{*}$ and $\mathrm{O}_{2} \cdots \mathrm{H}_{1}$ distance in $\mathbf{c}^{*}$ becomes shorter obviously. For examples, $\mathrm{N}_{1} \cdots \mathrm{H}_{1}$ length in $\mathrm{S}_{1}$ state is about $1.888 \AA$, which is about $0.007 \AA$ shorter than the one in $\mathrm{S}_{0}$ state; and $\mathrm{O}_{2} \cdots \mathrm{H}_{1}$ in $\mathrm{S}_{1}$ state is about 
$1.989 \AA$, obviously shorter than that in $\mathrm{S}_{0}$ state $(1.999 \AA)$. All these structural variations suggest that the intramolecular hydrogen bonds $\mathrm{N}_{1} \cdots \mathrm{H}_{1}-\mathrm{O}_{1}$ and $\mathrm{O}_{2} \cdots \mathrm{H}_{1}-\mathrm{O}_{1}$ in the $\mathrm{S}_{1}$ state was more stable than that in $\mathrm{S}_{0}$ state, as is consistent with the case in gas phase. The excited state hydrogen bond enhancement effect in gas phase and in $\mathrm{CHCl}_{3}$ solution is beneficial to the ESIPT process.

\subsection{Potential energy surfaces/curves and proton transfer process}

It's an effective method to construct the potential energy surfaces (PESs) and potential energy curves (PECs) for investigating the molecular properties and the phototautomeric reaction, and they could provide more intuitive information about the phototautomers and the ESIPT process. The calculations of PESs are performed using the constrained optimizations in the $\mathrm{S}_{0}$ state and $\mathrm{S}_{1}$ state geometrical structures of a along with the fixed $\mathrm{O}_{1}-\mathrm{H}_{1}$ bond length and $\mathrm{O}_{2}-\mathrm{H}_{2}$ bond length at the $\mathrm{B}_{3} \mathrm{LYP} / \mathrm{DZVP}$ level. Figure 1 illustrates the constructed PES in the $\mathrm{S}_{0}$ state as functions of the $\mathrm{O}_{1}-\mathrm{H}_{1}$ bond length and $\mathrm{O}_{2}-\mathrm{H}_{2}$ bond length, both of which fixed at values in the range from $0.99 \AA$ to $2.59 \AA$. It can be seen clearly that there exits four local energy minima on the ground state PES, and the coordinates of these points are (0.99 $\AA, 0.99 \AA),(0.99 \AA, 1.95 \AA),(1.95 \AA, 0.99$ $\AA)$ and $(1.95 \AA, 1.95 \AA)$. The $(0.99 \AA, 0.99 \AA)$ corresponds to the most stable a, the (1.95, 1.95 $\AA$ ) corresponds to the double-proton transfer tautomer a-2, $(0.99 \AA, 1.95 \AA)$ and (1.95, $0.99 \AA)$ correspond the same molecular structure, that is single-proton transfer tautomer a-1 (see Scheme 1). The calculated energy results show that the relative ordering of the potential energies for $\mathbf{a}, \mathbf{a}-\mathbf{1}$ and $\mathbf{a}-\mathbf{2}$ is as follows: $E_{\mathbf{a}}<E_{\mathbf{a}-1}<E_{\mathbf{a}-2}$, which suggests that the ground state intramolecular proton transfer (GSIPT) process of $\mathbf{a}$ is an endothermic reaction. This observation can be well understood through analyzing the structures of a, a-1 and a-2, as shown in Figure S1. The formation of the $\mathrm{O} \cdots \mathrm{H}-\mathrm{N}$ hydrogen bond in $\mathbf{a}-\mathbf{1}$ and $\mathbf{a}-\mathbf{2}$ tautomer decreases the aromaticity of $\mathbf{a}$ and leads to the losing large resonance energy of thiophene ring.

The potential barriers among these minima have also been calculated and the results show that the energy barrier of the direct double-proton transfer reaction $\mathbf{a} \rightarrow \mathbf{a - 2}$ is about $20.2 \mathrm{kcal} / \mathrm{mol}$, which is significantly higher than the ones of the single-proton transfer reaction $\mathbf{a} \rightarrow \mathbf{a - 1}(10.0 \mathrm{kcal} / \mathrm{mol})$ and $\mathbf{a}-\mathbf{1} \rightarrow \mathbf{a - 2}(10.7 \mathrm{kcal} / \mathrm{mol})$. The high energy barrier for $\mathbf{a}$ to $\mathbf{a}-\mathbf{2}$ tautomerization at $\mathrm{S}_{0}$ state discards any opptunity of the simultaneous intramolecular double-proton transfer process kinetically. In addition, the reverse proton transfer potential barriers among these minima have 
also been calculated. Our calculations show that the energy barrier of $\mathbf{a - 2} \rightarrow \mathbf{a}$ is about 6.88 $\mathrm{kcal} / \mathrm{mol}$; and the energy barriers of $\mathbf{a}-\mathbf{1} \rightarrow \mathbf{a}$ and $\mathbf{a - 2} \rightarrow \mathbf{a}-\mathbf{1}$ are $3.26 \mathrm{kcal} / \mathrm{mol}$ and $3.58 \mathrm{kcal} / \mathrm{mol}$, respectively. Therefore, backward GSIPT in a and $\mathbf{a}-\mathbf{1}$ is much faster than forward one, that is, $\mathbf{a}-\mathbf{1}$ and $\mathbf{a}-\mathbf{2}$ in the $\mathrm{S}_{0}$ state were inclined to tautomerize to $\mathbf{a}$ though the single proton transfer process or the simultaneous double proton transfer process.

The relaxed potential energy surface of $\mathbf{a}^{*}$ along the proton transfer pathway as a function of the reaction coordinates is shown in Figure 2. Similar with the PES at $\mathrm{S}_{0}$ state, four energy minima (0.99 ̊, $0.99 \AA),(1.99 \AA, 1.99 \AA),(0.99 \AA, 1.99 \AA)$, and $(1.99 \AA, 0.99 \AA)$ can be found on the PES, which corresponds to $\mathbf{a}^{*}, \mathbf{a}-\mathbf{2}^{*}$, and $\mathbf{a}-\mathbf{1}^{*}$, separately. The calculation results show that the energies of $\mathbf{a}-\mathbf{1}^{*}$ and $\mathbf{a}-\mathbf{2}^{*}$ are $3.41 \mathrm{kcal} / \mathrm{mol}$ and $4.24 \mathrm{kcal} / \mathrm{mol}$ lower, respectively, than that of $\mathbf{a}^{*}$, which means that the proton transfer at the $S_{1}$ state is an energetically favored process. In order to elucidate the proton transfer mechanisms in the ESIPT process, the potential barriers among these minima have also been calculated. The energy barrier for the conversion $\mathbf{a}^{*}$ to $\mathbf{a}-\mathbf{1}^{*}$ and the conversion $\mathbf{a}-1 *$ to $\mathbf{a}-2 *$ is predicted to be $6.76 \mathrm{kcal} / \mathrm{mol}$ and $5.50 \mathrm{kcal} / \mathrm{mol}$, respectively; the energy barrier for direct $\mathbf{a}^{*}$ to $\mathbf{a - 2} *$ transformation is estimated to be $6.91 \mathrm{kcal} / \mathrm{mol}$. These values indicate that both the successive single proton transfer process and the simultaneous double proton transfer process are likely to happen in the $S_{1}$ state, and thus, we can conclude that the single proton transfer mechanism and the double proton transfer mechanism should coexist in ESIPT process. Compared with forward reaction $\mathbf{a}^{*}$ to $\mathbf{a - 1}$ * and $\mathbf{a}^{*}$ to $\mathbf{a - 2}$, the energy barrier for revise $\mathbf{a}-1 *$ to $\mathbf{a}^{*}$ and $\mathbf{a - 2}$ * to $\mathbf{a}^{*}$ is relatively large; the potential barriers for transition from $\mathbf{a}-1 *$ to $\mathbf{a}^{*}$ and for transition from $\mathbf{a}-2 *$ to $\mathbf{a}^{*}$ are $10.17 \mathrm{kcal} / \mathrm{mol}$ and $11.15 \mathrm{kcal} / \mathrm{mol}$, respectively. Therefore, backward ESIPT in $\mathbf{a}^{*}$ is much slower than forward one. Combined with energy analysis above, it can be concluded that formations of $\mathbf{a}-1^{*}$ and $\mathbf{a}-\mathbf{2}^{*}$ molecules are kinetically and thermodynamically favored from $\mathbf{a} *$. The energy barrier for the reverse $\mathbf{a}-\mathbf{2} *$ to $\mathbf{a}-1 *$ process is estimated to be $6.33 \mathrm{kcal} / \mathrm{mol}$, slightly higher than the energy barrier for the $\mathbf{a}-1 *$ to $\mathbf{a}-\mathbf{2} *$ process $(5.50 \mathrm{kcal} / \mathrm{mol})$, and thus $\mathbf{a}-1 *$ to $\mathbf{a}-\mathbf{2} *$ tautomerization is faster than the revers process, and $\mathbf{a}-\mathbf{2} *$ may contribute more to fluorescence spectra.

Also, we studied the probable IPT process in $\mathbf{b}, \mathbf{b}^{*}, \mathbf{c}$, and $\mathbf{c}^{*}$. our calculation results showed that all the proton-transfer tautomers of $\mathbf{c}$ and $\mathbf{c}^{*}$ are not stable, and only one proton-transfer 
tautomer for $\mathbf{b}$ and $\mathbf{b}^{*}$ (named as $\mathbf{b}-\mathbf{1}$ and $\mathbf{b}-\mathbf{1}^{*}$ ) is relatively stable, as shown in Scheme 1. Thus, we performed the calculation of PECs of $\mathbf{b}$ using the constrained optimizations in the $\mathrm{S}_{0}$ state and $\mathrm{S}_{1}$ state geometrical structures along with the fixed $\mathrm{O}_{1}-\mathrm{H}_{1}$ bond length. The constructed PECs in the $\mathrm{S}_{0}$ and $\mathrm{S}_{1}$ states as functions of the $\mathrm{O}_{1}-\mathrm{H}_{1}$ length fixed at values in the range from $0.99 \AA$ to 2.49A. As shown in Figure 3, it can be found that the energies of $\mathbf{b}$ at $\mathrm{S}_{0}$ state increases along with lengthening of the $\mathrm{O}_{1}-\mathrm{H}_{1}$ bond from its stable structure (b), producing a potential barrier of 10.07 $\mathrm{kcal} / \mathrm{mol}$. It indicates that the GSIPT process is difficult to happen due to the high potential barrier in the process of the proton $\mathrm{H}_{1}$ transferring from $\mathrm{O}_{1}$ to $\mathrm{N}_{1}$. In terms of thermodynamics, GSIPT of b is an endothermic reaction and $\Delta \mathrm{H}=6.63 \mathrm{kcal} / \mathrm{mol}$, which indicates that the energy of molecular system is improved by $6.63 \mathrm{kcal} / \mathrm{mol}$ after the process of the proton $\mathrm{H}_{1}$ transferring from $\mathrm{O}_{1}$ to $\mathrm{N}_{1}$ in the $\mathrm{S}_{0}$ state. Therefore, it is unfavorable for the GSIPT process from the point of dynamics and thermodynamics. In comparison, it exhibits a barrier of $6.59 \mathrm{kcal} / \mathrm{mol}$ between the excited state equilibrium geometries of $\mathbf{b}^{*}$ and its stable phototautomer $\mathbf{b}-\mathbf{1}^{*}$, which is much lower than the one between $\mathbf{b}$ and $\mathbf{b}-\mathbf{1}$. Additionally, conversion of $\mathbf{b}^{*}$ to $\mathbf{b}-\mathbf{1}^{*}$ process is an exothermic process by releasing the energy of $0.99 \mathrm{kcal} / \mathrm{mol}$. Therefore, the intramolecular proton transfer process of $\mathbf{b}$ is kinetically and thermodynamically favorable at the $S_{1}$ state.

Besides, we also investigate the isomerization process between a-1 (a-1*) and b-1 (b-1*). The potential energy curves have been constructed for $180^{\circ}$ rotation around the inter-ring C-C bond in a-1 to forming b-1 at $S_{0}$ state and $S_{1}$ state, as shown in Figure 4. The calculated energies of b-1 and b-1* are greater than $\mathbf{a}-1$ and $\mathbf{a}-1 *$ by $4.4 \mathrm{kcal} / \mathrm{mol}$ and $14.9 \mathrm{kcal} / \mathrm{mol}$, respectively, indicating that the tautomer a-1 is more stable than b-1 at both $S_{0}$ state and $S_{1}$ state. At $S_{0}$ state, the energy barrier for $\mathbf{a}-\mathbf{1}$ to $\mathbf{b}-\mathbf{1}$ transformation is estimated to be $12.77 \mathrm{kcal} / \mathrm{mol}$, and the one for the reverse process is about $8.36 \mathrm{kcal} / \mathrm{mol}$, which means backward GSIPT is faster than forward one. Thus, b-1 is inclined to isomerize to a-1 in $\mathrm{S}_{0}$ state. Compared with barrier at $\mathrm{S}_{0}$ state, the energy barrier at $S_{1}$ state is much higher. The energy barrier for $\mathbf{a - 1} * \mathbf{b}-\mathbf{1}^{*}$ is about $40.61 \mathrm{kcal} / \mathrm{mol}$, and the energy barrier for $\mathbf{b}-\mathbf{1}^{*} \rightarrow \mathbf{a}-\mathbf{1}^{*}$ is about $20.70 \mathrm{kcal} / \mathrm{mol}$. These high energy barriers predicted by using $\mathrm{B}_{3}$ LYP method suggests that the isomerization reaction between $\mathbf{a - 1} *$ and $\mathbf{b}-\mathbf{1}^{*}$ is forbidden.

\subsection{Electronic spectra simulation and frontier molecular orbitals analysis}


Based on the above optimized geometries, we simulated the UV-Vis absorption spectra of $\mathbf{a}, \mathbf{b}$ and $\mathbf{c}$ in gas phase and in $\mathrm{CHCl}_{3}$ solvent. It can be seen that these UV-Vis absorption spectra for $\mathbf{a}, \mathbf{b}$ and $\mathbf{c}$ are nearly the same due to their similar structural character (see Figure S2). To deeply understand the spectra character, the exited states and the frontier molecular orbitals (FMOs) were analyzed in detail, which can provide information about the nature of the excited state conformations and qualitative discussion of charge distribution and charge-transfer. As shown in Table 2, our theoretical calculations show that there exists an intense $\mathrm{S}_{0} \rightarrow \mathrm{S}_{1}$ transition for $\mathbf{a}, \mathbf{b}$ and c in $\mathrm{CHCl}_{3}$ at $397 \mathrm{~nm}, 398 \mathrm{~nm}$, and $396 \mathrm{~nm}$, respectively, and an $\mathrm{S}_{0} \rightarrow \mathrm{S}_{2}$ transition for $\mathbf{a}, \mathbf{b}$ and $\mathbf{c}$ at $354 \mathrm{~nm}, 348 \mathrm{~nm}$, and $344 \mathrm{~nm}$, respectively. These absorption peaks are in good agreement with corresponding experimental absorption peaks (394nm and $354 \mathrm{~nm}) .{ }^{18}$ However, we cannot find the electron transition process corresponds with the maximum absorption at $372 \mathrm{~nm}$ in experiment. This absorption band may originate from the superposition of the absorption peaks from first singlet transition $\left(\mathrm{S}_{0} \rightarrow \mathrm{S}_{1}\right)$ and the second singlet transition $\left(\mathrm{S}_{0} \rightarrow \mathrm{S}_{2}\right)$ or molecular self-association. The first singlet excited states of $\mathbf{a}, \mathbf{b}$, and $\mathbf{c}$ are dominantly formed by the transitions from the highest occupied molecular orbital (HOMO) to the lowest unoccupied molecular orbital (LUMO); and the second excited states of $\mathbf{a}, \mathbf{b}$, and $\mathbf{c}$ are dominantly formed by the transitions from HOMO-1 to the LUMO. For sake of convenience, we take a as an example to discuss the charge distribution and charge-transfer upon excitation. The HOMO-1, HOMO, and LUMO of a are shown in Figure 5. The $\pi$ character of the HOMO as well as the $\pi^{*}$ character of the LUMO can be seen clearly, which allows description of the $S_{1}$ state as arising from a $\pi-\pi^{*}$-type transition. The natural bond orbital (NBO) analyses are adopted for a detailed investigation of the charge distribution over the atoms involved in intramolecular hydrogen bonds, which can be used as reasonable evidence to explore the tendency of excited state proton transfer reaction. As shown in Figure $\mathrm{S} 3$, the negative charge distribution localized on the $\mathrm{O}$ atom and $\mathrm{N}$ atom decreased from $\mathrm{S}_{0}$ state to $\mathrm{S}_{1}$ state, and the reduction for $\mathrm{O}$ atom is slightly more obvious. This charge redistribution shortens $\mathrm{N}_{1} \cdots \mathrm{H}_{1}$ bond length to some extent. The shapes of the HOMO-1 involved in $\mathrm{S}_{2}$ state are also shown in Figure 5, and it shows parital nonbonding character. Note that the distribution character of HOMO-1 is quite different from that of LUMO for a. The HOMO-1 is mainly localized on the 3,4-dihydroxythiophene moiety, whereas the LUMO distributes in the whole molecule. Therefore, the excitation to $S_{2}$ state involves intramolecular charge transfer from central 
3,4-dihydroxythiophene moiety to the bilateral groups. As a consequence, the electron density of the hydroxyl moiety decreases and the electron density localized on the $\mathrm{N}$ atom increases after transition from the HOMO-1 to the LUMO, as shown in Figure 5, which could enhance the intermolecular hydrogen bonds and promote proton transfer.

The fluorescence spectrum of $\mathbf{a}^{*}, \mathbf{b}^{*}, \mathbf{c}^{*}$ and their phototautomers in gas and $\mathrm{CHCl}_{3}$ are all simulated, and the results are shown in Figure 6. The excited state fluorescence maximum of $\mathbf{a}^{*}$, b*, and $^{*}$ are located at $490 \mathrm{~nm}, 493 \mathrm{~nm}$, and $495 \mathrm{~nm}$, respectively, which should correspond to the experimental absorption peak at $475 \mathrm{~nm}$. The red-shift of $\sim 93 \mathrm{~nm}$ can be ascribed to the normal Stokes shift. For single-proton transfer tautomer $\mathbf{a - 1}$, the the emission maximum is located at $419 \mathrm{~nm}$, which contribute to the experimentally observed values $412 \mathrm{~nm}$. In addition, another light emission maximum at around $500 \mathrm{~nm}$ has been calculated, which agrees well with the experimentally observed shoulder peak at $\sim 493 \mathrm{~nm}$. The emission band of $\mathbf{a}-1 *$ is red-shifted by about $10 \mathrm{~nm}$ in comparison with that of $\mathbf{a}^{*}$ according to our TDDFT calculation, and thus single-proton transfer process have very slight influence to fluorescence spectrum of $\mathbf{a}^{*}$. For $\mathbf{a}-\mathbf{2}^{*}$, double-proton transfer tautomer, three emission peaks localized at $565 \mathrm{~nm}, 427 \mathrm{~nm}$, and $420 \mathrm{~nm}$, respectively, which agree well with the experimentally observed values of $550 \mathrm{~nm}$ and $430 \mathrm{~nm}$. The excited state fluorescence of double-proton transfer tautomer largely shifts to red in comparison with the normal excited state fluorescence. Besides, the fluorescence spectrum for the single-proton transfer tautomer $\mathbf{b}-\mathbf{1}^{*}$ is also calculated and the results are also shown in Figure 6. The excited state fluorescence maximum of $\mathbf{b}-1 *$ is located at $411 \mathrm{~nm}$, which can be assigned to the experimentally observed values of $412 \mathrm{~nm}$. Another weak fluorescence peak at $510 \mathrm{~nm}$ has been calculated, but it may be covered by the other strong fluorescence peaks and is not observed in the experiment.

\section{Conclusions}

In summary, the excited state intramolecular single and double proton transfer (ESIPT) mechanisms of 2,5-bis(benzoxazol-2-yl) thiophene-3,4-diol were investigated in detail. Upon excitation, the intramolecular hydrogen bond $\mathrm{N}^{\cdots} \mathrm{H}-\mathrm{O}$ was significantly strengthened in the $\mathrm{S}_{1}$ state, which provides a driving force to effectively facilitate the proton transfer process. The reduced dimensionality PESs of a at $\mathrm{S}_{0}$ and $\mathrm{S}_{1}$ states were constructed, the forward and backward 
potential barriers among the minima points showed that the double proton transfer mechanism was implemented by transferring both protons along the two hydrogen bonds simultaneously or transferring the other proton after the single proton transfer. Moreover, the constructed PECs of $\mathbf{b}$ at the $\mathrm{S}_{0}$ and $\mathrm{S}_{1}$ states indicated that the intramolecular proton transfer process of the $\mathbf{b}$ is kinetically and thermodynamically favorable at the $\mathrm{S}_{1}$ state, with the $\mathrm{H}$ atom moving from $\mathrm{O}$ to $\mathrm{N}$. For the first time, it was found that the strong $\mathrm{N} \cdots \mathrm{H}-\mathrm{O}$ hydrogen bond in $\mathbf{b}$ conformation is further strengthened and the weak $\mathrm{O}{ }^{\cdots} \mathrm{H}-\mathrm{O}$ hydrogen-bond is further weakened in the excited state due to the stronger stabilization ability of $\mathrm{N} \cdots \mathrm{H}-\mathrm{O}$ hydrogen bond than $\mathrm{O} \cdots \mathrm{H}-\mathrm{O}$ hydrogen-bond. Based on the optimized thermodynamic stable conformations, the optical absorption properties and fluorescence properties were systematically investigated by the time-dependent density functional theory method. The experimental absorption spectrum was well reproduced by the calculated vertical excitation energies, and the assignment of absorption bands in experiments was confirmed. Also, the multiple fluorescence behavior of the fluorescence spectrum for 2,5-bis(benzoxazol-2-yl) thiophene-3,4-diol was predicted, which well explained the experimental observations. The fluorescence maxima at $475 \mathrm{~nm}$ is attributed to normal Stokes shifted emission; the large Stokes shifted fluorescence with peaks at $550 \mathrm{~nm}$ originates from the double proton transfer phototautomer emission, and the experimentally observed shoulder peak at $\sim 493 \mathrm{~nm}$ results from the excited state single proton transfer.

\section{Acknowledgements}

This work was supported by the National Science Foundation of China (Grant No. 21503034, $81601825,11304029,11274057,11474045,11474046)$, the Program for New Century Excellent Talents in University (Grant No. NCET-13-0702), Fundamental Research Funds for the Central Universities (Grant No. DC15013705, DC201502080203), Program for Science and Technology Project of Liaoning Province (Grant No. 201601237), Educational Committee Foundation of Liaoning Province (Grant No. L2015150), the Project of Liaoning Province (Grant No. 2012222009), the Program for Liaoning Excellent Talents in University (LNET) (Grant No. LR2015016), and the Science and Technique Foundation of Dalian (Grant No. 2014J11JH134, 2015J12JH201), and the Initial Funds for Imported Talents' Research Projects, Dalian 
Nationalities University (Grant No. 20136131). 


\section{References}

1. A. Weller, Naturwissenschaften, 1955, 42, 175-176.

2. R. Ali, S. S. Razi, P. Srivastava and A. Misra, Sensors and Actuators B-Chemical, 2015, 221, 1236-1247.

3. L. Cui, Y. Baek, S. Lee, N. Kwon and J. Yoon, Journal of Materials Chemistry C, 2016, 4, 2909-2914.

4. L. He, B. Dong, Y. Liu and W. Lin, Chemical Society Reviews, 2016, 45, 6449-6461.

5. W. Zhang, J. Yao and Y. S. Zhao, Accounts of Chemical Research, 2016, 49, 1691-1700.

6. M. J. Paterson, M. A. Robb, L. Blancafort and A. D. DeBellis, Journal of Physical Chemistry A, 2005, 109, 7527-7537.

7. A. P. Fluegge, F. Waiblinger, M. Stein, J. Keck, H. E. A. Kramer, P. Fischer, M. G. Wood, A. D. DeBellis, R. Ravichandran and D. Leppard, Journal of Physical Chemistry A, 2007, 111, 9733-9744.

8. D.-P. Li, J.-F. Zhang, J. Cui, X.-F. Ma, J.-T. Liu, J.-Y. Miao and B.-X. Zhao, Sensors and Actuators B-Chemical, 2016, 234, 231-238.

9. E. Karakus, M. Ucuncu and M. Emrullahoglu, Analytical Chemistry, 2016, 88, 1039-1043.

10. $\quad$ K. Zhang, S. Wu, D. Qu and L. Wang, Tetrahedron Letters, 2016, 57, 1133-1137.

11. V. S. Padalkar and S. Seki, Chemical Society Reviews, 2016, 45, 169-202.

12. A. Kundu, P. S. Hariharan, K. Prabakaran, D. Moon and S. P. Anthony, Crystal Growth \& Design, 2016, 16, 3400-3408.

13. T. Mutai, T. Ohkawa, H. Shono and K. Araki, Journal of Materials Chemistry C, 2016, 4, 3599-3606.

14. B. Tang, H. Liu, F. Li, Y. Wang and H. Zhang, Chemical Communications, 2016, 52, 6577-6580.

15. B. Tang, H. Zhang, K. Ye, H. Zhang and Y. Wang, Chemical Communications, 2016, 52, 13128-13131.

16. J. Zhao, J. Chen, Y. Cui, J. Wang, L. Xia, Y. Dai, P. Song and F. Ma, Physical Chemistry Chemical Physics, 2015, 17, 1142-1150.

17. J. Zhao, J. Chen, J. Liu and M. R. Hoffmann, Physical Chemistry Chemical Physics, 2015, 17, 11990-11999.

18. Y. Hao and Y. Chen, Dyes and Pigments, 2016, 129, 186-190.

19. G. W. T. M. J. Frisch, H. B. Schlegel, G. E. Scuseria, M. A. Robb, J. R. Cheeseman, G. Scalmani, V. Barone, B. Mennucci, G. A. Petersson, H. Nakatsuji, M. Caricato, X. Li, H. P. Hratchian, A. F. Izmaylov, J. Bloino, G. Zheng, J. L. Sonnenberg, M. Hada, M. Ehara, K. Toyota, R. Fukuda, J. Hasegawa, M. Ishida, T. Nakajima, Y. Honda, O. Kitao, H. Nakai, T. Vreven, J. A. Montgomery, Jr., J. E. Peralta, F. Ogliaro, M. Bearpark, J. J. Heyd, E. Brothers, K. N. Kudin, V. N. Staroverov, R. Kobayashi, J. Normand, K. Raghavachari, A. Rendell, J. C. Burant, S. S. Iyengar, J. Tomasi, M. Cossi, N. Rega, J. M. Millam, M. Klene, J. E. Knox, J. B. Cross, V. Bakken, C. Adamo, J. Jaramillo, R. Gomperts, R. E. Stratmann, O. Yazyev, A. J. Austin, R. Cammi, C. Pomelli, J. W. Ochterski, R. L. Martin, K. Morokuma, V. G. Zakrzewski, G. A. Voth, P. Salvador, J. J. Dannenberg, S. Dapprich, A. D. Daniels, Ö. Farkas, J. B. Foresman, J. V. Ortiz, J. Cioslowski, and D. J. Fox, Gaussian 09, Revision E.01, Gaussian, Inc., Wallingford CT, 2009. 
20. G.-Y. Li and T. Chu, Physical Chemistry Chemical Physics, 2011, 13, 20766-20771.

21. G.-Y. Li, G.-J. Zhao, Y.-H. Liu, K.-L. Han and G.-Z. He, Journal of Computational Chemistry, 2010, 31, 1759-1765.

22. C. T. Lee, W. T. Yang and R. G. Parr, Physical Review B, 1988, 37, 785-789.

23. O. Treutler and R. Ahlrichs, Journal of Chemical Physics, 1995, 102, 346-354.

24. J. Zhao and P. Li, Rsc Advances, 2015, 5, 73619-73625.

25. J. Zhao, H. Yao, J. Liu and M. R. Hoffmann, Journal of Physical Chemistry A, 2015, 119, 681-688.

26. H. Ma and J.-d. Huang, Rsc Advances, 2016, 6, 96147-96153.

27. A. Klamt and G. Schuurmann, Journal of the Chemical Society-Perkin Transactions 2, 1993, 799-805. 


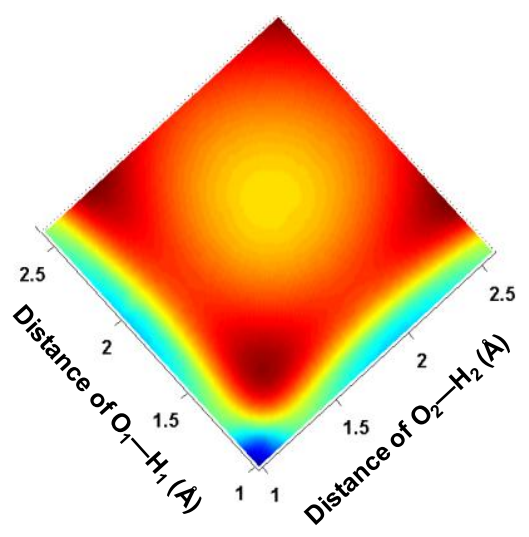

(a)

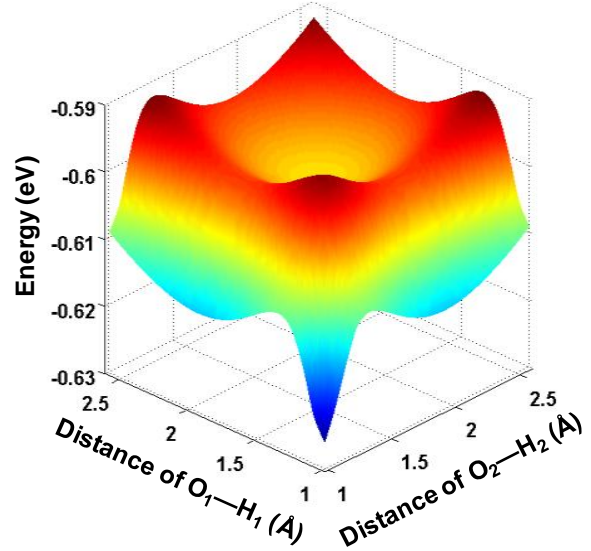

(b)

Figure 1. Potential engery surface of bis-2,5-(2-benzoxazolyl)-hydroquinone a at $S_{0}$ state as functions of the $\mathrm{O}_{1}-\mathrm{H}_{1}$ and $\mathrm{O}_{2}-\mathrm{H}_{2}$ lengths (a) on top view and (b) on side view. 


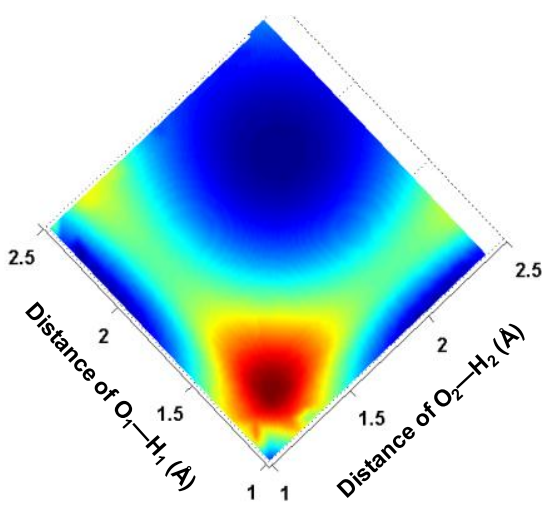

(a)

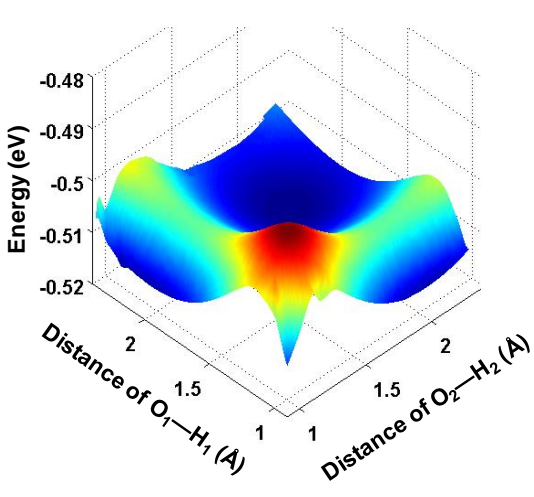

(b)

Figure 2. Potential engery surface of bis-2,5-(2-benzoxazolyl)-hydroquinone a at $S_{1}$ state as functions of the $\mathrm{O}_{1}-\mathrm{H}_{1}$ and $\mathrm{O}_{2}-\mathrm{H}_{2}$ lengths (a) on top view and (b) on side view. 


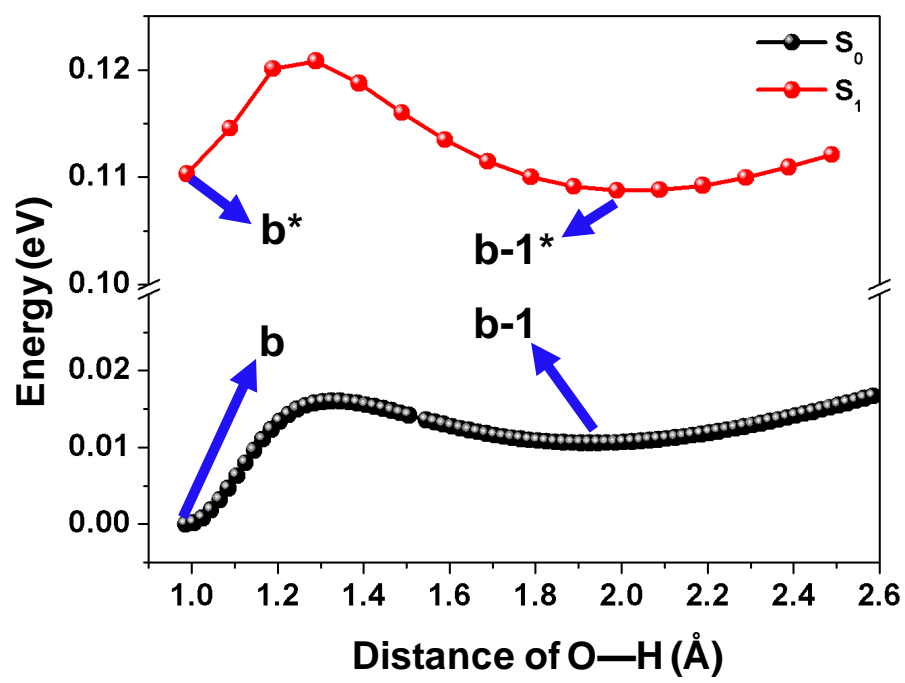

Figure 3. Potential energy curve of bis-2,5-(2-benzoxazolyl)-hydroquinone $\mathbf{b}$ as functions of the $\mathrm{O}_{1}-\mathrm{H}_{1}$ bond length at $\mathrm{S}_{0}$ state (black line) and $\mathrm{S}_{1}$ state (red line). 


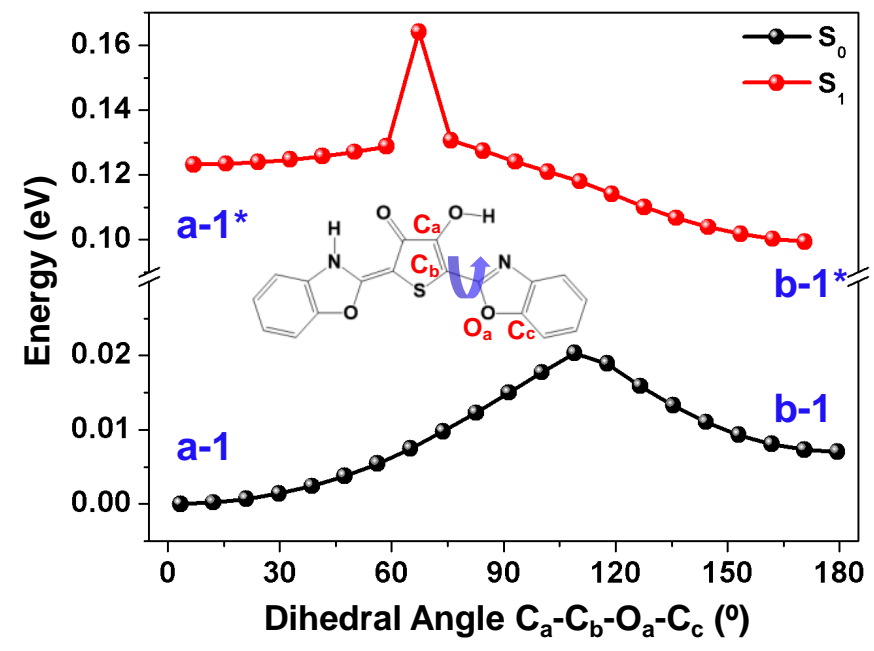

Figure 4. Variation of energy of bis-2,5-(2-benzoxazolyl)-hydroquinone as a function of rotation of the torsional angle for transformation from $\mathbf{a}-\mathbf{1}$ to $\mathbf{b}-\mathbf{1}$ (black line) and from $\mathbf{a}-\mathbf{1} *$ to $\mathbf{b}-\mathbf{1} *$ (red line). 

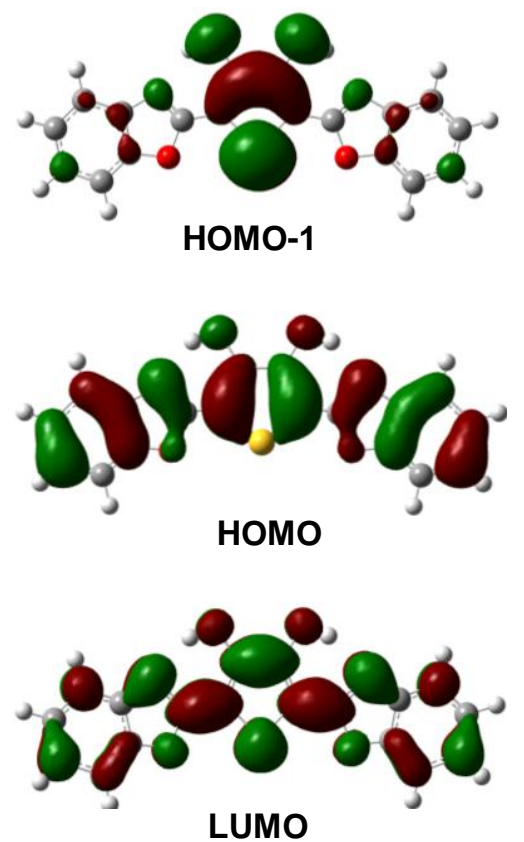

Figure 5. The shapes of HOMO-1, HOMO and LUMO involved in the $\mathrm{S}_{0} \rightarrow \mathrm{S}_{1}$ and $\mathrm{S}_{0} \rightarrow \mathrm{S}_{2}$ translations. 


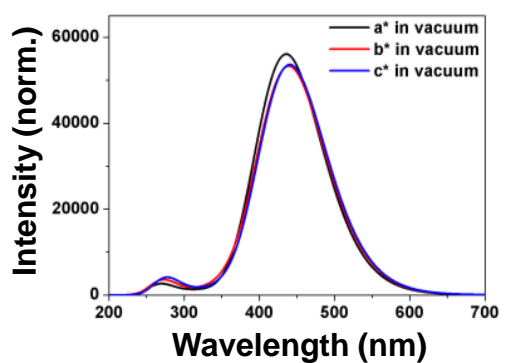

(a)

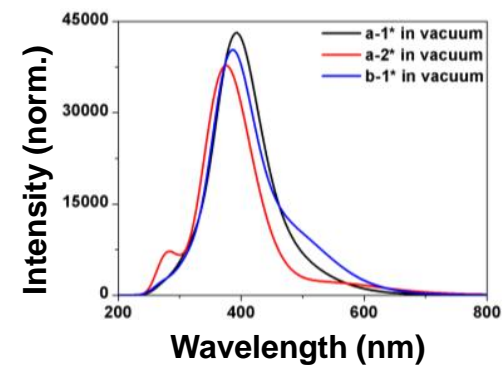

(c)

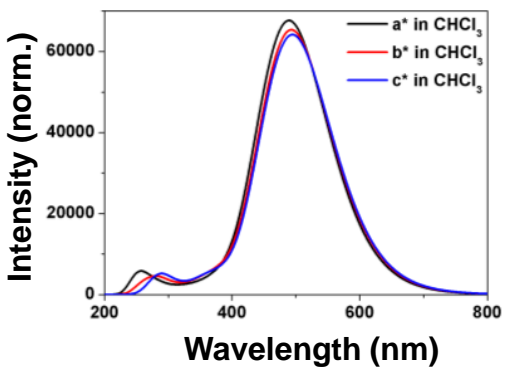

(b)

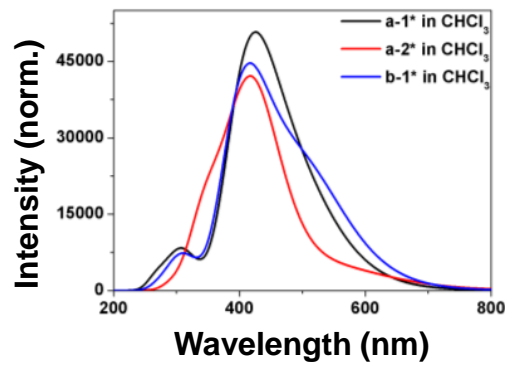

(d)

Figure 6. Calculated fluorescence spectra of $\mathbf{a}^{*}, \mathbf{b}^{*}$, and $\mathbf{c}^{*}$ in gas (a) and in $\mathrm{CHCl}_{3}$ solvent (b); and calculated fluorescence spectra of $\mathbf{a - 1}$, $\mathbf{a - 2}$, and $\mathbf{b}-\mathbf{1}^{*}$ in gas (c) and in $\mathrm{CHCl}_{3}$ solvent (d). 
Table 1. Calculated bond lengths, angles and dihedral angles of $\mathbf{a}, \mathbf{b}$, and $\mathbf{c}$ at $S_{0}$ state and $S_{1}$ state in gas and in $\mathrm{CHCl}_{3}$.

\begin{tabular}{|c|c|c|c|c|c|c|c|}
\hline Hydrogen bond para & & $\mathbf{a}$ & $\mathbf{b}$ & c & $\mathbf{a}\left(\mathrm{CHCl}_{3}\right)$ & $\mathbf{b}\left(\mathrm{CHCl}_{3}\right)$ & c $\left(\mathrm{CHCl}_{3}\right)$ \\
\hline \multirow{2}{*}{$\mathrm{L}_{\mathrm{O} 1-\mathrm{H} 1}(\AA)$} & $\mathrm{S}_{0}$ & 0.985 & 0.985 & 0.969 & 0.986 & 0.987 & 0.970 \\
\hline & $\mathrm{S}_{1}$ & 0.986 & 0.989 & 0.969 & 0.987 & 0.988 & 0.970 \\
\hline \multirow{2}{*}{$\mathrm{L}_{\mathrm{O} 2-\mathrm{H} 2}(\AA)$} & $\mathrm{S}_{0}$ & & 0.969 & & & 0.970 & \\
\hline & $\mathrm{S}_{1}$ & & 0.968 & & & 0.969 & \\
\hline \multirow{2}{*}{$\mathrm{L}_{\mathrm{N} 1 / \mathrm{O} 2 \cdots \mathrm{H} 1}(\AA)$} & $\mathrm{S}_{0}$ & 1.902 & 1.900 & 1.987 & 1.895 & 1.894 & 1.999 \\
\hline & $\mathrm{S}_{1}$ & 1.894 & 1.868 & 1.982 & 1.888 & 1.874 & 1.989 \\
\hline \multirow{2}{*}{$\mathrm{L}_{\mathrm{O} 3 \cdots \mathrm{H} 2}(\AA)$} & $\mathrm{S}_{0}$ & & 1.990 & & & 2.000 & \\
\hline & $\mathrm{S}_{1}$ & & 2.009 & & & 2.004 & \\
\hline \multirow{2}{*}{$\angle \mathrm{O} 1-\mathrm{H} 1 \cdots \mathrm{N} 1 / \mathrm{O} 2\left(^{\circ}\right)$} & $\mathrm{S}_{0}$ & 142.5 & 142.5 & 137.7 & 142.7 & 142.7 & 136.8 \\
\hline & $\mathrm{S}_{1}$ & 143.8 & 144.3 & 139.3 & 144.1 & 144.3 & 138.5 \\
\hline \multirow{2}{*}{$\angle \mathrm{O} 2-\mathrm{H} 2 \cdots \mathrm{O} 3\left(^{\circ}\right)$} & $\mathrm{S}_{0}$ & & 137.6 & & & 136.7 & \\
\hline & $\mathrm{S}_{1}$ & & 138.8 & & & 138.2 & \\
\hline \multirow{2}{*}{$\mathrm{D}_{\mathrm{N} 1 / \mathrm{O} 2-\mathrm{Cl}-\mathrm{C} 2-\mathrm{C} 3}\left({ }^{\circ}\right)$} & $\mathrm{S}_{0}$ & 2.9 & 2.8 & 0 & 2.9 & 2.8 & 0 \\
\hline & $\mathrm{S}_{1}$ & 3.1 & 3.3 & 0 & 3.4 & 3.4 & 0 \\
\hline \multirow{2}{*}{$\mathrm{D}_{\mathrm{O} 3-\mathrm{C} 4-\mathrm{C} 5-\mathrm{C} 6}\left({ }^{\circ}\right)$} & $\mathrm{S}_{0}$ & & 3.2 & & & 3.1 & \\
\hline & $\mathrm{S}_{1}$ & & 3.2 & & & 3.4 & \\
\hline
\end{tabular}


Table 2. Electronic excitation energies (nm), oscillator strengths, and the corresponding compositions for $\mathbf{a}, \mathbf{b}$, and c in gas and in $\mathrm{CHCl}_{3}$.

\begin{tabular}{|c|c|c|c|c|c|}
\hline & transition & $\lambda(\mathrm{nm})$ & $f$ & composition & $\mathrm{CI}$ \\
\hline \multirow{2}{*}{$\mathbf{a}$} & $\mathrm{S}_{0} \rightarrow \mathrm{S}_{1}$ & 381 & 1.3025 & $\mathrm{H} \rightarrow \mathrm{L}$ & $99.6 \%$ \\
\hline & $\mathrm{S}_{0} \rightarrow \mathrm{S}_{2}$ & 358 & 0.0602 & $\mathrm{H}-1 \rightarrow \mathrm{L}$ & $97.4 \%$ \\
\hline \multirow{2}{*}{ b } & $\mathrm{S}_{0} \rightarrow \mathrm{S}_{1}$ & 382 & 1.2320 & $\mathrm{H} \rightarrow \mathrm{L}$ & $99.3 \%$ \\
\hline & $\mathrm{S}_{0} \rightarrow \mathrm{S}_{2}$ & 351 & 0.1124 & $\mathrm{H}-1 \rightarrow \mathrm{L}$ & $96.5 \%$ \\
\hline \multirow{2}{*}{ c } & $\mathrm{S}_{0} \rightarrow \mathrm{S}_{2}$ & 380 & 1.2660 & $\mathrm{H} \rightarrow \mathrm{L}$ & $99.7 \%$ \\
\hline & $\mathrm{S}_{0} \rightarrow \mathrm{S}_{3}$ & 346 & 0.0583 & $\mathrm{H}-1 \rightarrow \mathrm{L}$ & $96.4 \%$ \\
\hline \multirow{2}{*}{ a $\left(\mathrm{CHCl}_{3}\right)$} & $\mathrm{S}_{0} \rightarrow \mathrm{S}_{1}$ & 397 & 1.4673 & $\mathrm{H} \rightarrow \mathrm{L}$ & $99.4 \%$ \\
\hline & $\mathrm{S}_{0} \rightarrow \mathrm{S}_{2}$ & 354 & 0.0856 & $\mathrm{H}-1 \rightarrow \mathrm{L}$ & $97.8 \%$ \\
\hline \multirow{2}{*}{$\mathrm{b}\left(\mathrm{CHCl}_{3}\right)$} & $\mathrm{S}_{0} \rightarrow \mathrm{S}_{1}$ & 398 & 1.4184 & $\mathrm{H} \rightarrow \mathrm{L}$ & $99.5 \%$ \\
\hline & $\mathrm{S}_{0} \rightarrow \mathrm{S}_{2}$ & 348 & 0.1056 & $\mathrm{H}-1 \rightarrow \mathrm{L}$ & $97.3 \%$ \\
\hline \multirow{2}{*}{ c $\left(\mathrm{CHCl}_{3}\right)$} & $\mathrm{S}_{0} \rightarrow \mathrm{S}_{1}$ & 396 & 1.4071 & $\mathrm{H} \rightarrow \mathrm{L}$ & $99.5 \%$ \\
\hline & $\mathrm{S}_{0} \rightarrow \mathrm{S}_{2}$ & 344 & 0.0874 & $\mathrm{H}-1 \rightarrow \mathrm{L}$ & $96.8 \%$ \\
\hline
\end{tabular}




\section{Graphical Abstract}

\section{Theoretical Investigation of Excited-State Single and Double Proton}

\section{Transfer Mechanisms for 2,5-bis(benzoxazol-2-yl)thiophene-3,4-diol}

Jin-Dou Huang ${ }^{1}$, Kun $\mathrm{Yu}^{2}$, Huipeng $\mathrm{Ma}^{*}{ }^{2}$, Shuo Chai ${ }^{3}$, and Dong Bin* ${ }^{1}$

${ }^{1}$ School of Physics and Materials Engineering, Dalian Nationalities University, Dalian 116600, China

${ }^{2}$ College of Medical Laboratory Science, Dalian Medical University, Dalian 116044, China

${ }^{3}$ School of Physics and Optoelectronic Technology, Dalian University of Technology, Dalian 116024, China

* Corresponding author. E-mail address: hpma@dlmedu.edu.cn (Huipeng Ma), and dong@dlnu.edu.cn (Bin Dong).

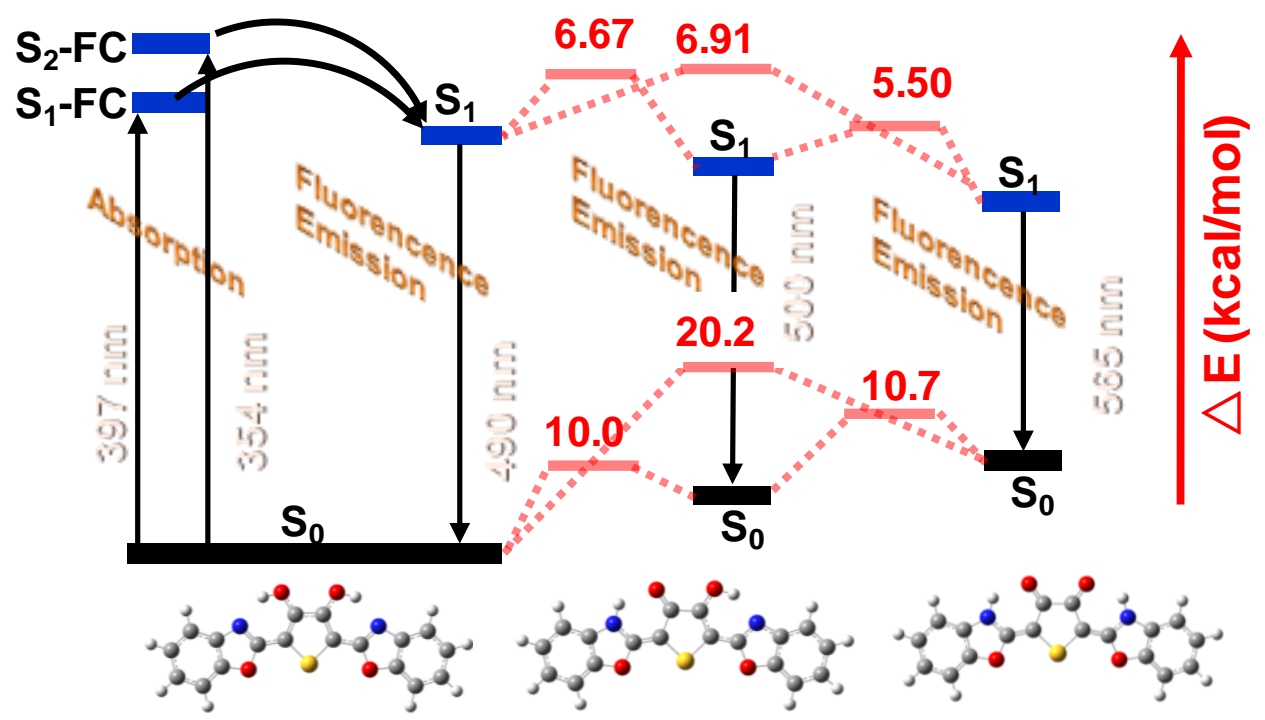

The schematic energy diagrams for photo-induced tautomerization of bis-2,5-(2-benzoxazolyl)-hydroquinone. 